\title{
PENDEKATAN HUKUM DALAM MENGATASI MASALAH E-COMMERCE DI INDONESIA
}

\author{
Heri Lilik Sudarmanto \\ Fakultas Hukum Universitas Kadiri \\ E-mail: hery_lilik@unik-kediri.ac.id
}

\begin{abstract}
Abstrak
Tujuan utama penelitian ini adalah untuk mengetahui strategi apa saja yang dapat digunakan untuk mengatasi masalah dalam e-commerce. Sejauh ini, berbagai penelitian dilakukan dan menyebutkan bahwa dari segi hukum bisnis masalah dalam e-commerce yang ada di Indonesia adalah customer protection yang belum memadai, regulasi pemerintah terutama penetapan pajak, tingginya biaya pemakaian data center dan penggunaan domain kode negara atau .id, transaksi jual beli yang masih rawan tindak penipuan, rendahnya jaminan kepastian hukum terhadap pelaku e-commerce, dan ancaman cyber security. Metode penelitian yang digunakan adalah berdasarkan pendekatan yuridis normatif mengenai aspek hukum bisnis melalui internet. Orisinalitas penelitian dapat ditelaah dari model pengembangan strategi dari hasil kajian hukum, penelitian terdahulu dan artikel terkait yang relevan saat ini. Melihat e-commerce terus berkembang, tentunya solusinya pun akan terus mengalami inovasi baru. Manfaat dari penelitian ini diharapkan memberikan kontribusi terhadap pengembangan $e$ commerce di Indonesia terutama bagi para stakeholder. Hasil penelitian menyimpulkan bahwa dalam tinjauan hukum masalah utama yang dihadapi saat ini adalah kepatuhan hukum. Solusinya yaitu menjamin keamanan transaksi e-commerce misalnya melalui asuransi, menciptakan lembaga bantuan upaya hukum bagi pengguna teknologi dan pemilik teknologi apabila terjadi pelanggaran transaksi e-commerce dan dukungan dari regulasi pemerintah terutama sanksi yang tegas merupakan salah satu kunci mengatasi masalah dalam e-commerce.
\end{abstract}

Kata kunci: hukum; masalah; perdagangan elektronik.

\begin{abstract}
The main objective of this research is to learn what strategies can be used to overcome problems in e-commerce. So far, various studies have been carried out and discussed the business legal aspects of problems in e-commerce that exist in Indonesia are inadequate customer protection, government regulations require taxation, increased costs of using data centers and use of country or .id domain domains, selling transactions purchases that are still prone to criminal acts, low guaranteed legal certainty to e-commerce, and theft of cyber security. The research method used is about juridical normative regarding aspects of business law through the internet. The originality of the study can be examined from the strategy development
\end{abstract}


model of the results of legal research, further research and relevant relevant articles at this time. Seeing e-commerce continues to grow, of course the solution will continue to be updated. The benefits of this research are expected to contribute to the development of e-commerce in Indonesia intended for stakeholders. The results of the study conclude how in solving legal problems that support the present is the resolution of the law. The solution is to guarantee the security of e-commerce transactions such as through insurance, providing assistance institutions with technological assistance and technology owners related to the occurrence of e-commerce transactions and agreed support from relevant government is one of the key solutions to problems in e-commerce.

Keywords: law; problems; e-commerce.

\section{Pendahuluan}

Industri e-commerce di Indonesia saat ini sangat kuat. Menurut data Statista.com pada taun 2015, penjualan e-commerce ritel sebesar 342,96 milyar AS dan diproyeksikan akan melampaui 600 milyar dollar AS pada tahun 2019. Selain itu, E-Niaga di Amerika Serikat diproyeksikan menghasilkan pendapatan sebesar 100 milyar dollar AS pada tahun 2019. ${ }^{1}$

"Kementerian Komunikasi dan Informatika (Kemkominfo) mengungkapkan bahwa terdapat beberapa masalah dalam e-commerce yaitu koneksi internet yang lambat, ancaman keamanan siber, perlindungan konsumen, logitik Indonesia yang mahal, kekurangan talenta digital, dan pajak bagi start up bisnis. Apabila masalah ini dapat teratasi dengan baik maka diharapkan perekonomian digital di Indonesia akan dapat mencapai US\$130 miliar atau sekitar Rp 1,88 triliun (Rp1,8 kuadrilliun; kurs Rp14.476) pada tahun 2020. Lebih lanjut dikatakan perlu memformulasikan bersama pemain ekosistem dan stakeholder di ekonomi digital untuk bekrjasama."2 Hasil pertemuan Asosiasi E-commerce Indonesia (IdEA) menyebutkan ada masalah yang harus diatasi agar industri $e$-commerce lokal dapat berkembang maju yaitu 1) mencari solusi menghadapi tantangan infrastruktur internet yang belum stabil dan transportasi yang sulit diandalkan serta prosedur perizinan dari bea cukai yang tidak efisien; 2) adanya ketergantungan

\footnotetext{
${ }^{1}$ Billionere.coach.co.id. 3 Masalah Utama yang Dihadapi Perusahaan E-commerce di Tahun 2018 beserta Solusinya. (28 november 2018). URL: https: / / billionairecoach.co.id/bisnis-online/3-masalah-utama-yang-dihadapi-perusahaan-ecommerce-di-tahun-2018-beserta-solusinya $08: 33$

${ }^{2}$ CNN Indonesia, (2019), Kominfo Sebut 7 Masalah E-commerce Indonesia. (21/05/2019, https: / / www.cnnindonesia.com/teknologi/20190521011413-185-396680/kominfo-sebut-7masalah-e-commerce-indonesia
} 
terhadap pembayaran tunai; 3) rendahnya kepercayaan konsumen dan keamanan dalam melakukan transaksi online; 4) stigma negatif e-commerce; 5) belum maksimalnya dukunga regulasi pemerintah bagi start up $e$ commerce terutama pelaku bisnis kecil dan menengah tertama terkait penetapan pajak; 6) penyelesaian perencanaan perlindungan industri $e$ commerce. ${ }^{3}$ Apabila masalah e-commerce bisa teratasi akan berdampak pada nilai ekonomi digital yang dapat mencapai lebih dari US\$130 miliar, dan ini membutuhkan formula yang cepat dan tepat.

Sekalipun telah disahkannya undang-undang ITE, menurut Debora Rosaria (Legal Manajer Bukalapak.com) dan Leo Faraytody (Business Development Director Easybiz), “mengungkapkan bahwa tidak ada dampak signifikan yang dirasakan bagi para pelaku e-commerce dari perubahan UU ITE tersebut. Bahkan sering terjadi kesalahpahaman dari konsumen tentang kerugian yang harus didertia konsumen akibat berita bohong dalam transaksi elektronik. Dimana dalam platform user-generated content telah dijelaskan bahwa marketplace tidak bertanggung jawab dengan barang yang tersedia dan dipromosikan, melainkan hanya sebagai penyedia sistem."

Perkembangan dan kemajuan teknologi saat ini telah mempengaruhi paradigma hukum. Menurut Richard Susskind, "paradigma sudah harus diubah terutama information service karena masyarakat dapat dengan mudah memperoleh jawaban atas persoalan hukum hanya dengan akses internet tanpa harus membayar. Selain itu, dalam rangka mengoptimalisasikan pemanfaatan potensi ekonomi berbasis elektronik maka harus dilakukan berbagai upaya berbaikan dan formulasi terhadap sumber-sumber potensi penyelesaian hambatan dan tantangan e-commerce untuk saat ini dan dimasa yang akan datang. Dalam hal ini peran pemerintah sangat dibutuhkan oelh karena itu tinjauan penelitian dari segi hukum memang sangat dibutuhkan. ${ }^{5}$

Basu berpendapat bahwa teknologi seperti e-commerce berkembang sangat cepat, akibatnya terjadi kesenjangan temporal yang jelas antara inovasi teknologi dan perubahan hukum. Dari sis negatif yang diakibatkan adalah kesenjangan waktu mempromosikan ketidakpastina hukum dimana pihak yang terkena dampak tidak bisa sepenuhnya memahami hak dan kewajiban hukum mereka. Sisi positinya, jeda waktu dapat memungkinkan

\footnotetext{
${ }^{3}$ Nadine Freisclad, (2015), Enam Masalah utama yang menjadi pemain e-commerce lokal dan solusi yang diharapkan dari pemerintah. (09 April 2015, 16:26 WIB). techinaasia.com. URL: https://id.techinasia.com/solusi-rudiantara-pemerintah-kominfomasalah-ecommerce-indonesia

${ }^{4}$ Hukumonline, 2016, Harapan Pelaku E-commerce Indonesia Pasca UU ITE Baru. URL: https://www.hukumonline.com/berita/baca/Lt5863491859ad2/harapan-pelaku-e-commerceindonesia-pasca-uu-ite-baru/

${ }^{5}$ I. Lukito, 2017, Tantangan Hukum dan Peran Pemerintah Dalam Pembangunan ECommerce. JIKH 11(3): pp. 349-367.
} 
lebih banyak varian analisis dan pemikiran yang lebih bijaksana sebelum impelelmntasi kebijakan. Kecenderungan teknologi tidak mampu untuk diprediksi, seingga memungkinkan untuk adanya reformasi hukum setelah implikasi perubahan teknologi dapat lebih dipahami. ${ }^{6}$

Berbagai masalah baru yang bermunculan seiring dengan meningkatnya e-commerce di Indonesia mmbutuhkan perlindungan secara hukum atas resiko-resiko yang mungkin terjadi dalam praktiknya. Bahkan faktanya, walaupun regulasi pemrintah dan UU ITE telah diperbarui, berbagai bentuk pelanggaran masih terus terjadi terutama kasus penipuan, ketaatan pajak, dan ancaman cybercrime. Oleh karena itu, berdasarkan latar belakang masalah diatas, penulis melakukan kajian lebih lanut mengenai formulasi strategi yang harus dilakukan dalam menyikapi berbagai masalah dalam $e$ commerce di Indonesia.

\section{Permasalahan}

Berdasarkan uraiaan latar belakang yang telah dikemukakan maka pada tulisan ini akan membahas permasalahan pada pertama, transaksi pelaksanaan e-commerce dalam kajian hukum ? bagaimana konsep pendekatan hukum dalam mengatasi permasalahan pada e-commerce di Indonesia?

\section{Metode Penelitian}

Metode pendekatan yang digunakan adalah metode yuridis normatif atau penelitian hukum doktrinal, dimana penelitian hukum berkaitan dengan permasalahan dalam e-commerce di Indonesia. Penelitian menggunakan data sekunder yang didapatkan dari bahan hukum primer dan hukum sekunder.

Sumber hukum bisnis meliputi dua macam yaitu 1) Asas kontrak perjanjian dari pihak yang terlibat dimana masing-masing pihak harus patuh pada aturan yang telah disepakti dan 2) Asas kebebasan kontrak yang mana pelaku bisnis bisa membuat dan menentukan isi perjanjian yang mereka sepakati sebelumnya. Secara umum sumber hukum bisnis berdasarkan perundang-undangan di Indonesia meliputi;1) Hukum Dagang (KUH) Dagang); 2) Peraturan Perudang-undangan diluar KUH Pidana, KUH Perdata dan KUH Dagang; 3) Hukum Perdata (KUH) Perdata) dan Hukum Publik (Pidana Ekonomi/KUH Perdata). Sedangkan untuk implementasi kegiatan e-commerce dalam rangka memberikan kepastian hukum dan perlindungan hukum bagi stakeholder mengacu pada Undang-Undang No. 11 tahun 2008 tentang Informasi dan Elektronik (UU ITE), Road Map e-Commerce (Peta Jalan Sistem

\footnotetext{
${ }^{6}$ S. Basu, Global perspectives on e-commerce taxation law. Routledge, 2016.
} 
Perdagangan Nasinal Berbasis Elektronik) Tahun 2017-2019 dan Perpres Nomor 74 Tahun 2017

\section{Pembahasan}

\section{Transaksi Pelaksanaan E-Commerce Dalam Kajian Hukum}

World Trade Organization (WTO) menerangkan tentang ruang lingkup cakupan e-commerce yang terdiri dari bidang produksi, distribusi pemasaran, penjualan, dan pengiriman barang atau jasa melalui elektronik. Sedangkan Fuady menjelskan bahwa kegiatan e-commerce dilakukan dengan berorientasi pada pembelian on line (online transaction), Komunikasi digital (digital communication), Penyedia jasa (service), proses bisnis dengan sistem dan sasaran untuk meningkatkan otomatisasi, dan market of one yang dapat mengadaptasikan produk dan jasa sesuai dengan kebutuhan bisnis.

Menurut Basu (2016), element dalam e-commerce terdiri dari tiga lapisan yaitu, "1) it exist as 'physical' infrastructure- as a data network 'managed' at a high level by international bodies and a day-to-day level by various public bodies and corporations whose networks it uses; 2) it exits as a 'service' infrastructure provided bi ISPs who offer accers to the intenet; and 3) it exits at the level of users."

"Dalam pasal 1 angka 10 dalam Undang-Undang Tentang Informasi dan Transaksi Elektronik (UU ITE), disebutkan bahwa transaksi elektronik adalah perbuatan hukum yang dilakukan dengan menggunakan komputer, jaringan komputer atau media elektronik lainnya." Menurut Makarim, para stake holder dalam e-commerce mempunyai hak dan kewajiban sebagaimana diatur dalam undang-undang. antara lain; “1) pelaku usaha adalah penjual/merchant/pengusaha yang menawarkan sebuah produk melalui intenet; 2) pembeli/konsuen merupakan setiap orang yang tidak dilarang oleh undang-undang untuk melakukan transaksi jual beli yang ditawarkan oleh pelaku usaha; 3) Bank sebagai pihak penyalur dana dari pembeli/konsumen kepada pelaku usaha; dan 4) Provider yaitu penyedia jasa layanan akses internet. ${ }^{7}$

Adapun kategori implementasi e-commerce adalah 1) Ubiquity merupakan teknologi yang selalu tersedia di sepanjang waktu dan tidak membutuhkan tempat seperti halnya transkasi perdaganngan konvensional; 2) Global Reach memungkinkan terjalinnya hubungan perdagangan lintas budaya, batasan wilayah namun dengan biaya yang lebih efektif; 3) ecommerce bersifat Universal standards; 4) Richness, dimana informasi yang tersedia lebih kompleks dan sangat variatif; 5) Interactivity, memungkinkan

\footnotetext{
${ }^{7}$ E. Makarin, Kompilasi hukum Telematika, PT. Gravindo Persada, Jakarta, 2000.
} 
untuk melakukan komunikasi jarak jauh antara pelaku binis dan konsumen, 6) Infomrmation Density, menekan biaya proses, pemyimpanan dan komunikasi serta meningkatkan kualitas dari informasi yang tersedia dari segi ketepatan waktu, jumlah dan akurasinya;7) Personalization dan customization yang memungkinkan mempersonalisasikan pesan berdasarkan produk/jasa yang dikirimkan berdasarkan pilihan, keinginan, dan riwayat pembelian konsumen; dan 8) Social tecnology dapat memungkinkan penggunanya untuk berinteraksi secara sosial dengan komunitas dunia maya. ${ }^{8}$

Menurut Traver dan Laudon (2014), ada enam tipe e-commerce berdasarkan aktivitasnya sebagaimana tabel dibawah ini;

Tabel 1.1.Enam Tipe E-commerce berdasarkan aktivitas

\begin{tabular}{|l|l|l|}
\hline No & \multicolumn{1}{|c|}{ Tipe } & \multicolumn{1}{c|}{ Penjelasan } \\
\hline 1 & $\begin{array}{l}\text { E-commerce bisnis ke } \\
\text { konsumen }\end{array}$ & $\begin{array}{l}\text { Bisnis penjualan online dari unit bisnis ke } \\
\text { konsumen individual }\end{array}$ \\
\hline 2 & $\begin{array}{l}\text { E-commerce bisnis ke } \\
\text { bisnis }\end{array}$ & $\begin{array}{l}\text { Bisnis penjualan online dari unit bisnis ke } \\
\text { unit bisnis lainnya }\end{array}$ \\
\hline 3 & $\begin{array}{l}\text {-commerce sosial } \\
4\end{array}$ & $\begin{array}{l}\text { Eemungkinkan terjadinya jaringan sosial } \\
\text { dan hubungan sosial secara online }\end{array}$ \\
\hline 5 & Mobile e-commerce konsumen & $\begin{array}{l}\text { Bisnis penjualan online dari konsumen ke } \\
\text { konsumen lainnya }\end{array}$ \\
\hline 6 & $\begin{array}{l}\text { E-commerce lokal } \\
\text { melalui penggunaan alat mobile }\end{array}$ \\
\hline
\end{tabular}

Sumber: Traver dan Laudon (2014) ${ }^{9}$

Sedangkan berdasarkan SE-62/PJ/2013 e-commerce diklasifikasikan dalam empat kegiatan besar, antara lain; 1) Online Marketplace yaitu kegiatan menyediakan tempat kegiatan usaha berupa Toko internet atau Mall Internet; 2) Classified Ads merupakan kegiatan menyediakan tempat/dan atau waktu untuk memajang content barang dan atau jasa bagi pengiklan untuk memasang iklan yang ditujukan kepada pengguna iklan melalui situs yang telah disediakan oleh penyelenggaran CA; 3) Daily Deals adalah kegiatan menyediakan tempat kegiatan usaha berupasitus DD sebagai tempat DD menjual barang/jasa kepada pembeli dengan menggunkan voucer sebagai alat pembayaran; dan 4) Online Retail yaitu kegiatan menjual baang/jasa

${ }^{8}$ K. C. Laudon \& C. G. Traver, E-commerce 2014: Business, Technology, Society, Tenth Edition, 3rd penyunt., Prentice Hall, New Jersey, 2014.

'Ibid., 
yang diselenggarakan oleh penyelenggara kepada pembeli di situs online retail.

Adapun faktor-faktor yang menyebabkan transaksi elektronik berkembang pesat dimasyarakat antara lain dikarenakan; 1) e-commerce mempunyai kemampuan untuk menjangkau lebih banyak pelanggan dan lebih efisien waktu karena konsumen dapat mengakses secara terus menerus; 2) $e$ commerce mendorong kreatifitas pihak penjual dan pendistribusian informasi secara cepat dan tepat; 3) e-commerce dapat menciptakan efisiesni tinggi, murah serta informatif; 4) e-commerce dapat meningkatkan kepuasan pelanggan. ${ }^{10}$ Sedangkan Desruelle dan Burgelman menyebutkan lima faktor lain yaitu; 1) globalisasi dan liberalisasi perdagangan; 2) kompetisi yng semakin tajam; 3) perkembangan teknologi; 4) pengurangan tujuan secara fisik; dan 5) publisitas. ${ }^{11}$

Pada tabel berikut ini, keuntungan-keuntungan yang diperoleh bagi para stakeholder e-commerce diantaranya;

Tabel 1.2. Keuntungan Menggunakan E-commerce

\begin{tabular}{|c|c|c|}
\hline No & Stakeholder & Dampak Positif \\
\hline 1 & Bagi perusahaan & $\begin{array}{l}\text { a. Memperluas pangsa pasar bisnis } \\
\text { b. Menghemat biaya operasional karena } \\
\text { tidak harus membuka tempat usaha } \\
\text { berbentuk fisik } \\
\text { c. Meningkatkan pelayanan konsumen } \\
\text { terutama kredibilitas perusahaan } \\
\text { atau UMKM } \\
\text { d. Memperpendek jarak secara fisik } \\
\text { hanya dengan mengklik situs yang } \\
\text { diinnginkan }\end{array}$ \\
\hline 2 & Bagi konsumen & $\begin{array}{l}\text { a. Konsumen dapat memperoleh } \\
\text { informasi dan bertransaksi setiap } \\
\text { saat, cepat, dan murah sehingga } \\
\text { dinilai lebih efektif } \\
\text { b. Biaya operasional terutama transport } \\
\text { dapat ditekan serendah mungkin } \\
\text { c. Harga yang ditawarkan relatif lebih } \\
\text { terjangkau } \\
\text { d. Konsumen dapat melakukan transaski }\end{array}$ \\
\hline
\end{tabular}

10 I. Safitri, (1999), E-commerce Dalam Perspektif Hukum. On Line Journal http://business.fortunecity/com/buffett/842/art080399_ecommerce.htm.

${ }_{11}$ P. Desruelle \& J. C. Burgelman, The impact of e-commerce on the value chain. info, 3(6), 2001. hlm. 485-497. 


\begin{tabular}{|c|c|c|}
\hline & & $\begin{array}{l}\text { dari berbagai tempat sehingga lebih } \\
\text { fleksibel } \\
\text { e. Aman secara fisik karena tidak } \\
\text { membutuhkan uang fisik pada saat } \\
\text { melakukan transaksi e-commerce }\end{array}$ \\
\hline 3 & Bagi masyarakat & $\begin{array}{l}\text { a. Membuka peluang usaha baru } \\
\text { b. Memberikan pelaung konsumen untuk } \\
\text { memperoleh barang-barang } \\
\text { berkualitas dengan harga yang } \\
\text { bervariasi }\end{array}$ \\
\hline
\end{tabular}

Sumber: Oetomo, $2001^{12}$

Aspek hukum (cyberlaw) adalah ketentuan hukum yang mengatur tentang mekanisme dan sistem yang mampu melindungi, menjaga dan memberikan keamanan kepada setiap pihak yang menggunakan internet sebagai sarana transaksi atau menyampaikan informasi yang tergolong dapat mempengaruhi dan mendorong pihak untuk ikut atau membeli informasi yang disampaikan tersebut. Sebagai sarana informasi tidak dibenarkan melakukan pencurian, perusakan informasi dan perbuatan yang tergolong pidana sehingga dapat dikenakan sanksi hukuman pidana. ${ }^{13}$

"Kontrak online atau syarat sah perjanjian dalam transaksi ecommerce diatur dalam pasal 1320 Kitab Undang-Undang Hukum perdata (KUHPer) yang terdiri dari empat syarat sahnya suatu perjanjian yaitu; 1) Adanya kesepakaan para pihak dan tidak terdapat unsur paksaan atas dasar pendapat pihak yang dirugikan untuk keperluan pembatalan; 2) Kecakapan para pihak sebagaimana diatur dalam pasal 1330 KUH Perdata (belum dewasa dan berada dibawah pengampuan); 3) Adanya objek perjanjian yang terdiri dari barang dalam bentuk fisik dan dapat disesuaikan dengan jenisnya; dan 4) penyebab yang halal karena sebab yang tidak halal berlawanaan dengan norma kesusilaan atau ketertiban umum."

"Pasal 7 Undang-Undang No.8/1999 tentang Perlindungan Konsumen (UU Perlindungan Konsumen) yang mengatur bahwa seorang penjual sebagai pelaku usaha wajib memberikan ganti rugi kepada pembeli atau konsumen apabila barang yang diterima tidak sesuai dengan perjanjian. Hal ini dilakukan agar konsumen dapat menuntut haknya apabila terjadi penipuan atas produk yang telah dibeli dari penjual online." Sedangkan hak penjual berdasarkan Pasal 6 UU Perlindungan Konsumen adalah 1) menentukan dan menerima harga pembayaran atas penjualan barang yang sesua dengan

${ }^{12}$ Budi S.D. Oetomo, Perspektif E-commerce, Andi. Yogyakarta, 2001.

13 I. Safitri. (1999). Op. , cit 
kesepakatan antara penjual dan pembeli; 2) memperoleh perlindungan hukum dari tindakan pembeli yang beritikad tidak baik; 3) hak untuk melakukan pembelaan diri sepatutnya dalam sengketa pengadilan; 4) hak untuk rehabilitasi nama baik apabil terbukti secara hukum merugikan konsumen yang tidak diakibatkan oleh barang dan atau jasa yang diperdagangkan."

Ada hak dan kewajiaban pembeli barang/jasa secara online sebagaiman diatur dalam pasar 5 UU Perlindugnan Konsumen sebagai berikut; 1) membaca informasi dan mengikuti prosedur atau petunjuk tentang penggunaan atau jasa yang dibelinya; 2) beritikad baik dalam melakukan transaski jual beli barang atau jasa tersebut; 3) membayar harga pembelian sesuai dengan yang telah disepakti; 4) mengikuti upaya penyelesaian hukum secara patut apabila dikemudian hari akan timbul sengketa dari proses jual beli tersebut. Sedangkan untuk melindungi pembeli sebagai konsumen dari hal-hal yang merugikan onsumen atas perbuatan yang tidak bertanggung jawab yang dilakukan penjual. Pasal 4 UU Perlindungan Konsumen menjelaskan hak-hak konsumen adalah; 1) hak atas kenyamanan, keamanan, dan keselamatan dalam mengkonsumi barang dan atau jasa; 2) hak memilih serta mendapatkan barang dan atau jasa dengan kondisi yang sesuai dengan yang telah diperjanjiakan sebelummnya; 3) memperoleh informasi secara benar, jujur dan jelas mengenai barang/jasa yang dipublikasikan; 4) memperoleh pelayanan dan perlakuan secara benar dan tidak diskriminatif; 5) didiengarkan pendapatnya atau keluhannya atas kondisi barang/jasa yang dibelinya; 6) mendapatkan perlindungan hukum secara patut apabila dari proses jual beli tersebut timbul sengketa; 7) mendapatkan kompensasi atau ganti rugi apabila barang dan atau jasa yang dibelinya tidak sesuai dengan apa yang dijanjiakan; dan 8) mendapatkan pembinaan dan pendidikan konsumen.

\section{Konsep Pendekatan Hukum Dalam Mengatasi Permasalahan Pada E- Commerce Di Indonesia}

Firmansyah menyebutkan terdapat dua kendala implementasi ecommerce di Indonesia yaitu Pertama adalah kendala yang bersifat teknis seperti belum tersedianya standar baku yang mengatur tentang mutu $e$ commerce, keamanan dan masalah jaringan atau web server. Kedua yaitu kendala yang bersifat non teknologi diantaranya adanya persepsi masyarakat bahwa transaksi e-commerce rawan penipuan dan pajak yang cukup tinggi. Lebih lanjut dijelaskan bahwa para pelaku bisnis e-commerce mengeluhkan biaya memakai data center yang jauh lebih mahal dibandingkan data center 
di luar negeri dan pemakaian domain lokal yang sering menyulitkan situs $e$ commerce untuk bersaing di level global. ${ }^{14}$

Persaingan di e-commerce berdampak pada bidang-biang pendukung lanskapnya. Para pelaku bisnis e-commerce terutama dibidang logistics dan payment dapat dikuasai oleh pelaku bisnis e-commerce yang mempunyai pangsa besar. Yang mengkhawatirkan adalah apabila tidak adanya payung hukum yang kuat, suplier produk lokal akan tergantikan oleh produk-produk asing karena tidak mampu bersaing dan berinovasi sejalan dengan perkembangan e-commerce. ${ }^{15}$

Menurut Riswadi (2002), ada beberapa hal yang harus diatur dalam transaksi e-commerce, meliputi; 1) pengaturan tentang cukai dan pajak dengan sanksi yang tegas namun tidak memberatkan start up bisnis dalam penggunaan aplikasi e-commerce; 2) ketentuan hukum yang berhubungan dengan privacy dan keamanan yang berpihak kepada stakeholder; 3) kemampuan dan dukungan jaringan infrastruktur telekomunikasi dan stadnar teknis dalam perdagangan elektronik secara jelas dan akurat; 4) dan pengaturan masalah yuridiksi serta applicable law. Riswadi (2002) juga menjelaskan bahwa pemilihan bentuk undang-ndang sangat dibutuhkan atas dasar pertimbangan bahwa kedudukannya lebih kuat dibandingkan peraturan pemerintah dan keputusan presiden. ${ }^{16}$

Selain masalah yang telah disebut diatas, penyalahgunaan oleh pihak yang tidak bertangugn jawab juga dapat terjadi dan kegagalan sistem ini dapat berakibat negatif diantaranya; “1) kehilangan segi finansial secara langsung karena kecurangan yang dilakukan oleh pihak yang tidak bertanggunjawab; 2) pencurian informasi yang bersifat rahasia sehingga menimbulkan hilangnya rasa kepercayaan dari konsumen; dan 3) kehilangan kesempatan bisnis karena gangguan pelayanan misalnya karena akibat kesalhan yang bersifat non teknis. Kerugian ini merupakan suatu yang tidak terduga dan sulit untuk diprediksi secara akurat namun perlu diantisipasi terutama yang diakibatkan dari faktor eksternal seperti pada kesalahan sistem elektronik atau faktor manusia." 17

14 A. Firmansyah, Kajian Kendala Implementasi E-Commerce di Indonesia. Jurnal Masyarakat Telematika dan Informasi 8(2): 2017, $\mathrm{hlm}$. 127-136. https://media.neliti.com/media/publications/233789-kajian-kendala-implementasi-ecommerce-d-51b46c9d.pdf

${ }^{15}$ Law-justice. Co., 2019, Tanpa Ada Kepastian Hukum, Bisnis e-Commerce Indonesia Jadi Bancakan Asing. URL: https://www.law-justice.co/artikel/39623/tanpa-ada-kepastianhukum-bisnis-e-commerce-indonesia-jadi-bancakan-asing/

${ }^{16}$ Budi A. Riswadi, Regulasi Hukum dalam Transaksi E-Commerce: Menuju Optimalisasi Pemanfaatan Teknologi Informasi. Jurnal Hukum 19(9): 2002, hlm. 135-144.

${ }_{17}$ O. Hartono, Aspek Hukum Pengembangan Usaha Melalui Internet. Seminar Nasional Teknologi \& Komunikasi Terapan 2011 (Sematik 2011). 
Basu (2016) mengungkapkan bahwa e-commerce menciptakan konteks yang paling cocok untuk transaksi bisnis di mana teori inti, prinsip, aturan dan kebijakan perpajakan internasiooanl dapat diperiksa, ditantang dan dipertimbangkan kembali atas dasar; 1) e-commerce internasional akan terus tumbuh; 2) bahwa penyebaran e-commerce akan menyebabkan lebih banyak tantangan pada sistem yang ada terutama masalah pajak; 3) pemerintah nasional pada akhirnya akan menuntut perpajakan digital; 4) untuk pengumpulan pajak yang efektif membutuhkan teknologi dan akan membutuhkn juga koordinasi internasional yang luas. ${ }^{18}$

E-commerce disatu sisi mampu meningkatkan kecepatan volume transaski barang/jasa dan mengurangi biaya pembelian dan produsen secara nyata namun e-commerce memiliki masalah dan cacat dalam keamanan informasi. Jika enkripsi tidak digunakan secara benar maka dapat menyebabkan masalah kemanan. ${ }^{19} \mathrm{Hal}$ ini dapat diperburuk dengan situasi kesenjangan perdagangan bebas dan pasar liberal antara negara maju dan negara berkembang. Kesenjangan digital telah mengungkapkan perbedaan yang tajam antara keduanya dan perambahan seringkali muncul dan menjadi masalah kritis yang cukup mempengaruhi bisnis e-commerce khususnya bagi bisnis waralaba. ${ }^{20}$ Internet meningkatkan resiko antara pewaralaba dan pemilik waralaba ketika franchisor menghadapi situs web transaksional menjadi outlet dimana-mana'. ${ }^{21}$

Pengembangan e-commerce sejatinya membutuhkan penyesuaian dengan sumber daya dan situasi lingkungan yang ada.Ini, jika diikuti oleh investasi dalam infrastruktur telekomunikasi, iklim hukum dan peraturan yang memungkinkan reformasi dan pelatihan kelembagaan yang sehat dan pendidikan sumber daya manusia yang akan memastikan bahwa negara berkembang seperti Indonesia merupakan pesaing kuat dalam e-commerce global. $^{22}$

Adapun langkah-langkah strategis yang dapat dilakukan terdiri dari dua macam formulasi yaitu; Mengembangkan layanan e-pembayaran; Menanamkan kepercayaan pelanggan dengan menekankan bahwa ecommerce mempunyai komitmen sertifikasi sistem yang kuat; Membuat

\footnotetext{
${ }^{18} \mathrm{~S}$. Basu, Global perspectives on e-commerce taxation law. Routledge, 2016.

${ }^{19}$ M. Abbasi \& A. Zare, Information Security in E-Commerce Law. UCT Journal of Social Sciences and Humanities Research, 4(03), 2016. hlm. 12-16.

${ }^{20}$ Adel. A. Alyoubi, E-commerce in Developing Countries and how to Develop them during the Introduction of Modern Systems, Procedia Computer Science 65(2015). Pp. 479483. https://doi.org/10.1016/j.procs.2015.09.127

${ }^{21} \mathrm{G}$. Cliquet \& E. Voropanova, E-commerce and encroachment: evidence from French franchise networks. Journal of Marketing Channels, 23(3), 2016, hlm. 114-128.

${ }^{22}$ Adel A. Alyoubi, 2015, Op., cit
} 
aktivitas e-commerce sebagai kegiaan yang bersifat universal, yang dalam perencanaan pembangunannya menginkutsertakan stakeholder dalam perencanaan dan insentif bagi perusahaan UMKM sehingga diharapkan dapat tumbuh menajdi berusahaan yang mandiri dan besar. ${ }^{23}$; Pengaturan ecommerce dalam undang-undang harus mengatur tentang kewajiban bagi pelaku usaha untuk memberikan identitasnya secara jelas, mencantumkan spesifikasi produk harus detail, mekanisme pembayaran dan mekanisme pengiriman jelas untuk memberikan kepastian waktu kpaan dan bagaimana barang diterima; Dukungan infrastruktur-infrastruktur teknis dalam $e$ commerce agar terealisasi secara baik. ${ }^{24}$; Sebagai marketplace, harus tersedia sistem sortir komoditas yang dipasarkan dalam e-commerce; Meningkatkan jumlah sumber daya manusia dibidang legal information engineers untuk mengantisipasi kemungkinan dampak buruk transaksi ecommerce. ${ }^{25}$; Enkripsi yang digunakan dalam keamanan informasi harus secara baik dan benar untuk mengubah informasi menjadi kode yang tidak seorang pun dapat menggunakannya kecuali pengguna yang diizinkan bahka $\mathrm{n}$ orang lain tidak dapat mengaksesnya. Dengan menggunakna enkripsi maka informasi elektronik dan non elektronik dapat ditransmisikan dan disimpan. Enkripsi dapat menyediakan fasilitas berupa keamana informasi dengan meningkatkan metode otentifikasi, kompresi pesan, tanda tangan digital, kemampuan non-repudiation, dan komunikasi jaringan terekripsi; ${ }^{26}$ Untuk mengatasi e-encroachment, A web-to-store-strategy dan the click-andcollect system dapat dilaksanakan sebagaiman telah dilakukan di pasar Amerika Serikat dan sebagian besar jaringan supermarket Perancis. ${ }^{27}$

Sebagaimana telah diketahui bahwa yang menjadi kendala non teknis dalam e-commerce adalah masalah kebijakan pemerintah. E-commerce tidak dapat berkembang dengan baik apabila tidak didukung sepenuhnya oleh pemerintah Indonesia. Thierer mengungkapkan ada lima prinsip kebijakan untuk mendukung'sustanaibilty' e-commerce sebagaimana pada tabel berikut ini;

Selain prinsip-prinsip kebijakan yang dikemukakan diatas, berikut ini tambahan prinsip dari kebijakan perdagangan secara elektronik yang diterangkan oleh Edmon Makarin dalam artikelnya yang berjudul Kerangka

${ }^{23}$ A. Firmansyah, Op., cit.

${ }^{24}$ Margaretha R. Anjani \& B. Santoso, Urgensi Hukum E-commerce di Indonesia. Jurnal Law Reform 14(1): 2018, hlm. 89-103.

${ }^{25}$ M. Lauritsen, Richard Susskind, Transforming the Law: Essays on Technology, Justice and the Legal Marketplace.(Book Review). Artificial Intelligence and Law, 9(4), 2001, hlm. 295-303.

${ }^{26}$ M. Abbasi \& A. Zare, Op., cit

${ }^{27} \mathrm{G}$. Cliquet \& E. Voropanova, E-commerce and encroachment: evidence from French franchise networks. Journal of Marketing Channels, 23(3), 2016, hlm. 114-128. 
Kebijakan Dan Reformasi Hukum untuk Kelancaran Perdagangan Secara elektronik (E-commerce) di Indonesia yaitu; “1) perdagangan dibangun atas dasar itikad baik dan menghargai asas saling percaya terhadap akuntabilitas sistem elektronik yang baik; 2) perdagangan secara elektronik harus efisien dan efektif sehingga kendala biaya ekonomi tinggi diminimalisasikan; 3) perdagangan diharapkan dapat menumbuhkan iklim persaingan yang sehat dan 4) dapat memberikan kemudahan dan melindungi kepentingan konsumen serta mencegah setiap upaya untuk eksploitasi hak-hak konsumen. ${ }^{28}$

Proses kemudahan dalam legalitas juga sangat dibutuhkan terutama bagi start up bisnis e-commerce. Daniel Tumiwa, Ketua Indonesia Ecommerce Association (IdEA) menyatakan bahwa proses legalitas merupakan pintu masuk bagi UMKM dalam mengembangkan bisnisnya e-commerce sehingga sudah seharusnya tersinkron dengan regulasi lintas departemen supaya tidak terjadi tumpang tindih dan memberikan porsi bagi invesotor asing agar bisnis e-commerce tidak tercatat dalam daftar negatif investasi. $E$ commerce juga membutuhkan peraturan hukum perpajakan yang adil dan netral dalam perkembangannya. ${ }^{29}$

Menurut Edmon Makarim, “terdapat tiga perlindungan hukum yang diharuskan ada di dalam perjanjian e-commerce yaitu; 1) perlindungan hukum bagi penjual terutama aturan yang jelas mengenai jangka waktu pembayaran sehingga penjual tidak dipersalahkan apabila penjual menjual barang/jasa yang telah dipesan karena telah lewat batas waktu pembayaran; 2) perlindungan bagi pelanggan dimana konsumen memperoleh barang/jasa yang sesuai dengan kualifikasi yang ditawarkan diawal perjanjian dan dapat memperoleh jaminan ganti rugi apabila barang tidak sesuai dengan pesanan; 3) dan perlindungan data pribadi konsumen yang dapat diakomodir dengan menggunakan privacy policy atau kebijakan privasi." 30

Riswadi menjelaskan apabila dalam peraturan perudang-undangan belum mengatur secara spesifik mengenai transaski e-commerce bukan berarti apabila terjadi sengketa kemudian tidak dapat diselesaikan. Ada dua pendekatan hukum yang dapat dilakukan yaitu; "Pertama, pendekatan hukum konvensional (exsiting law) yang dilakukan atas dasar analogi hukum dimana hakim tidak boleh menolak perkara dengan alasan tidak ada

28 E. Makarim, Kerangka Kebijakan dan Reformasi Hukum Untuk Kelancaran Perdagangan secara Elektronik (E-Commerce) di Indonesia. Jurnal Hukum \& Pembangunan, 44(3), 2014. hlm. 314-337.

${ }^{29}$ B. K..Yapar, S. Bayrakdar \& M. Yapar, The role of taxation problems on the development of e-commerce. Procedia-Social and Behavioral Sciences, 195, 2015, hlm. 642648 .

${ }^{30}$ E. Makarim, Tanggung Jawab Hukum Penyelenggaraan Sistem Elektronik, Rajawali pers. Jakarta, 2010. 
hukumnya (ius curia novit). Dan kedua, masalah pengakuan pembuktian terhadap data elektronik dapat disiasati dengan cara membuat aturan yang disepakati kedua belah pihak yang bersengketa atau desibut dengan istilah selfregulation. ${ }^{31}$ Berkaca dari beberapa tinjauan dalam rancangan Hukum Keamanan Internet Tiongkok (ISL) dan Hukum E-commerce (ECL) dimana adanya otoritarianisme konsultatif dalam sistem pembuatan undang-undang dapat menyebabkan rezim otoriter dalam kerangka hukum yang terkadang responsif dan konsultatif, terfragmentsi dan dapat menimbulkan manipulasi kekuasaan. Hal ini perlu diantisapai para pembuat kebijakan agar tidak menghasilakn rancangan undang-undang ITE yang terpolarisasi secara tidak masuk akal. Oleh karena itu kontrol kepemimpinan harus dibatasi oleh konstitusi dan batasan-batasan tersebut harus diberikan kekuatan substantif untuk menjadi nyata dan praktis. ${ }^{32}$

\section{Penutup}

\section{Simpulan}

Masalah-masalah yang menjadi kendala pengembangan e-commerce di Indonesia membutuhkan formula strategis yang harus dirancang dan dilaksanakan secara cepat dan tepat. Hal ini dilakukan mengingat bahwa perkembangan e-commerce global juga sangat cepat. Apabila tidak melakukan tindakan akselerasi dari segi hukum bisnis maka dikhawatirkan masalah akan semakin memperburuk kondisi e-commerce lokal dan konsumen tentunya. Dengan kata lain, strategi teknis dan non teknis diharapkan dapat membantu merumuskan kebijakan pemerintah yang lebih baik lagi dan berpihak tidak hanya terhadap start up bisnis e-commerce lokal tetapi juga dapat memberikan perlindungan bagi konsumen.

\section{Saran}

Kepada pemerintah harus segera merumuskan dalam sebuah aturan khusus mengenai perdagangan online yang mengatur ketentuan secara spesifik dan memberikan perlindungan kepada para pihak tentunya sesuai dengan kebiasaan masyarakat Indonesia. khusus kepada masyarakat jika instrumen hukum belum memungkinkan maka pemahaman terhadap perdagangan yang bersifat online harus dipahami dengan mendalam kiranya dapat mencegah kerugian yang lebih besar.

${ }^{31}$ Budi A. Riswadi, Regulasi Hukum dalam Transaksi E-Commerce: Menuju Optimalisasi Pemanfaatan Teknologi Informasi. Jurnal Hukum 19(9): 2002, hlm. 135-144.

32 J. Deng \& P. Liu, Consultative Authoritarianism: The Drafting of China's Internet Security Law and e-Commerce Law. Journal of Contemporary China, 26(107), 2017, hlm. 679-695. 


\section{Daftar Pustaka}

\section{Buku}

Budi S.D. Oetomo, Perspektif E-commerce, Andi, Yogyakarta, 2001.

E. Makarin, Kompilasi hukum Telematika, PT. Gravindo Persada, Jakarta, 2000.

E. Makarim, Tanggung Jawab Hukum Penyelenggaraan Sistem Elektronik. Rajawali pers, Jakarta, 2010.

Lauritsen, M. (2001). Richard Susskind, Transforming the Law: Essays on

Technology, Justice and the Legal Marketplace.(Book Review). Artificial Intelligence and Law, 9(4), 295-303.

Laudon, K. C. \& Traver, C. G. E-commerce 2014: Business, Technology, Society, Tenth Edition, 3rd penyunt., New Jersey: Prentice Hall, 2014.

Munir Fuady, Pengantar Hukum Bisnis, Citra Aditya Bakti, Bandung, 2005.

I. Safitri, E-commerce Dalam Perspektif Hukum, 1991.

\section{Jurnal}

Budi A. Riswadi, Regulasi Hukum dalam Transaksi E-Commerce: Menuju Optimalisasi Pemanfaatan Teknologi Informasi. Jurnal Hukum 19(9): 2002. pp. 135-144.

B. K., Bayrakdar, Yapar S., \& Yapar, M. The role of taxation problems on the development of e-commerce. Procedia-Social and Behavioral Sciences, 195, (2015). 642-648.

E. Makarim, Kerangka Kebijakan dan Reformasi Hukum Untuk Kelancaran Perdagangan secara Elektronik (E-Commerce) di Indonesia. Jurnal Hukum \& Pembangunan, 44(3), (2014) 314-337.

G. Cliquet, \& Voropanova, E.. E-commerce and encroachment: evidence from French franchise networks. Journal of Marketing Channels, 23(3), (2016) 114-128.

I. Lukito. Tantangan Hukum dan Peran Pemerintah Dalam Pembangunan ECommerce. JIKH 11(3): 2017 pp. 349-367.

J., Deng \& Liu, P. Consultative Authoritarianism: The Drafting of China's Internet Security Law and e-Commerce Law. Journal of Contemporary China, 26(107), (2017). 679-695.

Margaretha R. Anjani \& Santoso, B. Urgensi Hukum E-commerce di Indonesia. Jurnal Law Reform 14(1): 2018. pp. 89-103.

M. Abbasi, \& Zare, A. Information Security in E-Commerce Law. UCT Journal of Social Sciences and Humanities Research, 4(03), (2016) 12-16.

P., Desruelle \& Burgelman, J. C.. The impact of e-commerce on the value chain. info, 3(6), (2001). 485-497. 


\section{Internet}

A. Firmansyah Kajian Kendala Implementasi E-Commerce di Indonesia. Jurnal Masyarakat Telematika dan Informasi 8(2): 2017 pp. 127-136. https://media.neliti.com/media/publications/233789-kajian-kendalaimplementasi-e-commerce-d-51b46c9d.pdf

Adel. A Alyoubi. E-commerce in Developing Countries and how to Develop them during the Introduction of Modern Systems, Procedia Computer Science 65(2015). Pp. 479-483. https://doi.org/10.1016/j.procs.2015.09.127

CNN Indonesia. Kominfo Sebut 7 Masalah E-commerce Indonesia. (21/05/2019, 08:33 WIB). cnnindonesia.com. URL: https://www.cnnindonesia.com/teknologi/20190521011413-185396680/kominfo-sebut-7-masalah-e-commerce-indonesia

Hukumonline.com. 2015. Ini Tantangan Hukum UKM Berbisnis E-Commerce. URL: https://www.hukumonline.com/berita/baca/lt5551bbfa38bfc/initantangan-hukum-ukm-berbisnis-e-commerce/

Hukumonline. Harapan Pelaku E-commerce Indonesia Pasca UU ITE Baru. URL: 2016.https://www.hukumonline.com/berita/baca/lt5863491859ad2/har apan-pelaku-e-commerce-indonesia-pasca-uu-ite-baru/

Law-justice. Co. Tanpa Ada Kepastian Hukum, Bisnis e-Commerce Indonesia Jadi Bancakan Asing. 2019. URL: https://www.lawjustice.co/artikel/39623/tanpa-ada-kepastian-hukum-bisnis-ecommerce-indonesia-jadi-bancakan-asing/

Nadine Freisclad. Enam Masalah utama yang menjadi pemain e-commerce lokal dan solusi yang diharapkan dari pemerintah. (09 April 2015, 16:26 WIB). techinaasia.com. URL: https://id.techinasia.com/solusirudiantara-pemerintah-kominfo-masalah-ecommerce-indonesia

O. Hartono Aspek Hukum Pengembangan Usaha Melalui Internet. Seminar Nasional Teknologi \& Komunikasi Terapan 2011 (Sematik 2011).

S.Basu,. Global perspectives on e-commerce taxation law. Routledge.Billionerecoach.co.id. 3 Masalah Utama yang Dihadapi Perusahaan E-commerce di Tahun 2018 beserta Solusinya. (28 november 2018). 2016. URL: https://billionairecoach.co.id/bisnis-online/3masalah-utama-yang-dihadapi-perusahaan-e-commerce-di-tahun-2018beserta-solusinya 